\title{
New aspects of delirium in elderly patients with critical limb ischemia
}

This article was published in the following Dove Press journal:

Clinical Interventions in Aging

28 September 2015

Number of times this article has been viewed

\author{
Willem A van Eijsden' \\ Jelle W Raats' \\ Paul GH Mulder ${ }^{2}$ \\ Lijckle van der Laan' \\ 'Department of Surgery, ${ }^{2}$ Amphia \\ Academy, Amphia Hospital, Breda, \\ the Netherlands
}

Correspondence: Willem A van Eijsden Department of Surgery, Amphia Hospital, PO Box 905 I8, 4800 RK Breda, the Netherlands

Tel +3I 765955450

Email wvaneijsden@amphia.nl
Objective: The primary objective was to identify possible risk factors for delirium in patients with critical limb ischemia undergoing surgery. The secondary objective was to study the effect of delirium on complications, the length of hospital stay, health care costs, and mortality.

Methods: All patients 65 years or older with critical limb ischemia undergoing surgery from February 2013 to July 2014 at Amphia Hospital, were included and followed up until December 31, 2014. Delirium was scored using the Delirium Observation Screening Scale (DOSS). Perioperative risk factors (age, comorbidity, factors of frailty, operation type, hemoglobulin, and transfusion) were collected and analyzed using logistic regression. Secondary outcomes were the number of complications, total hospital stay, extra health care costs per delirium, and mortality within 3 months and 6 months of surgery.

Results: We included 92 patients with critical limb ischemia undergoing surgery. Twenty-nine (32\%) patients developed a delirium during admission, of whom 17 (59\%) developed delirium preoperatively. After multivariable analysis, only diabetes mellitus (odds ratio $[\mathrm{OR}]=6.23 ; 95 \%$ confidence interval $[\mathrm{CI}]: 1.11-52.2 ; P=0.035)$ and Short Nutritional Assessment Questionnaire for Residential Care (SNAQ-RC) $\geq 3$ (OR =5.55; 95\% CI: $1.07-42.0 ; P=0.039$ ) was significantly associated with the onset of delirium. Delirium was associated with longer hospital stay $(P=0.001)$, increased health care costs, and higher mortality after 6 months $(P<0.001)$.

Conclusion: Delirium is a common adverse event in patients with critical limb ischemia undergoing surgery with devastating outcome in the long term. Most patients developed delirium preoperatively, which indicates the need for early recognition and preventive strategies in the preoperative period. This study identified undernourishment and diabetes mellitus as independent risk factors for delirium.

Keywords: confusion, frailty, vascular surgery, bypass surgery, amputation, risk factors, costs

\section{Introduction}

Currently, delirium is a serious problem in vascular surgery. ${ }^{1}$ Due to the aging of the population, the incidence of delirium will continue to increase among vascular patients.

The incidence rates of postoperative delirium vary between $2 \%$ and $72 \%$ depending on the type of surgery performed. ${ }^{2}$ This wide variation is related to the issues of definition, differences in the diagnostic tools used, and the different populations studied.

Most of the studies concerning delirium focus on orthopedic or cardiothoracic surgery. 3,4 Postoperative delirium is of major importance due to the many related adverse effects, such as prolonged hospital stay, decrease in functional status, increase in health care cost, morbidity, and mortality. ${ }^{5-9}$

Delirium is a serious adverse event that is often unrecognized by medical practitioners. Most importantly, delirium is preventable in an estimated one-third of the cases with simple nonpharmacological interventions performed by dedicated nursing staff. ${ }^{10,11}$ 
It is of major importance to identify patients at risk for delirium in order to initiate these preventive strategies in time. The identified risk factors after vascular surgery are age, previous major amputation, end-stage renal failure, and cognitive impairment. ${ }^{9}{ }^{12-15}$ Interestingly, Sasajima et al reported that patients with critical limb ischemia develop delirium more frequently compared to patients with intermittent claudication, ${ }^{9}$ however, in their study, only patients with bypass surgery were included, and the sample size was small.

Critical limb ischemia is the most advanced stage of peripheral arterial disease in which revascularization is needed for limb salvage. ${ }^{16}$ Limb amputation is the last treatment option when revascularization is no longer possible. This leaves the patient in a reduced functional status. ${ }^{17}$ Moreover, serious systemic atherosclerosis increases the likelihood of adverse cardiovascular events leading to higher perioperative morbidity and mortality. ${ }^{18}$ These factors contribute to the frail condition of patients with critical limb ischemia and puts them at risk for developing a delirium in a hospitalized setting. ${ }^{12,14,19}$ Currently, information about the predisposing factors for delirium in patients with critical limb ischemia is lacking. Therefore, in this study, we analyze the incidence, perioperative risk factors, and the outcome of perioperative delirium in patients with critical limb ischemia undergoing surgery.

\section{Patients and methods Patient selection}

A retrospective study on prospectively collected data was performed lasting from February 2013 to December 2014. This research was based on regular patient care, the medical ethical committee of the Amphia Hospital in Breda, the Netherlands, permitted this project and waived informed consent. All patients 65 years or older with critical limb ischemia undergoing surgery from February 2013 to July 2014 at Amphia Hospital, were included and followed up until December 31, 2014. Critical limb ischemia was defined as stage 4-6 according to the Rutherford classification for peripheral arterial occlusive disease..$^{20}$ All patients were admitted to our vascular surgical ward of Amphia Hospital, Breda, the Netherlands. Treatment options were discussed in a multidisciplinary consultation between radiologists and vascular surgeons. Patients eligible for surgical treatment were selected based on comorbidity, age, and overall condition. If the patient was too fragile to undergo the planned revascularization procedure, or when revascularization was unlikely to lead to a functional limb, a primary amputation was discussed with the patient and, when desirable, performed.
We excluded patients with a hospital stay shorter than 2 days because it takes at least a full day to identify an incidence of delirium. For this reason, patients receiving endovascular treatment were also excluded, since almost all of these patients had a hospital stay shorter than 2 days.

Multiple possible risk factors for delirium were collected during admission, including preoperative, operative, and postoperative data.

\section{Preoperative factors}

Basic patient characteristics of all included patients were collected, including age, sex, and comorbidities. Severity of vascular disease was classified according to the Fontaine classification.

Comorbidities were divided into the following categories: cardiac disease (myocardial infarction, rhythm disorder, valve disorder, cardiomyopathy, and cardiac failure), pulmonary disease (chronic obstructive pulmonary disease and asthma), renal impairment (defined as glomerular filtration rate $<60 \mathrm{~mL} / \mathrm{min} / 1.73 \mathrm{~m}^{2}$ ), neurological disorder (cerebrovascular accident, transient ischemic attack, dementia, or Parkinson's disease), and vascular risk factors (hypertension, diabetes mellitus type 1 or 2 , and hypercholesteremia).

Other factors related to delirium such as a delirium history and/or visual impairment and daily use of alcohol were extracted from the electronic medical records. A patient was counted as visually impaired if he/she required the use of glasses/contact lenses for daily activities. If no visual aid was needed by the patient, or if it was needed for reading only, no visual impairment was noted. Similar format and rules were applied to hearing impairment. A person was counted as having hearing impairment if he/she needed hearing aids for basic communications. We were able to prospectively collect all available parameters during the study period using a full electronic patient file: Hyperspace Version IU4 (Epic Inc., Verona, WI, USA).

\section{Frailty}

Frailty depends on multiple patient-related factors such as functional status, nutritional status, and cognitive status. Physical impairment was scored using the Katz Index of Independence in Activities of Daily Living (Katz-ADL). ${ }^{21}$ This instrument assesses functional status by measuring the patient's ability to perform daily activities independently. A score of 6 indicates full function, and a score of 5 or lower indicates any physical impairment.

The nutritional status was scored with the Short Nutritional Assessment Questionnaire for Residential Care (SNAQ-RC) 
score. ${ }^{22}$ SNAQ-RC is an adapted and validated version of the more widely used SNAQ score and adds body mass index as a contributory parameter. An SNAQ-RC score of 3 or higher is considered as high risk for undernourishment.

The care dependency (receiving daily care in a nursing home or by home care at home) and living situation (at home or in a nursing home) prior to admission in the hospital were noted. All patients living in a nursing home were care-dependent due to some degree of either cognitive or physical impairment.

\section{Operative data}

Pre- and postoperative biochemistry data were collected, including hemoglobulin $(\mathrm{Hb})$ levels. Anemia was defined as a $\mathrm{Hb}<7.6 \mathrm{mmol} / \mathrm{L}$ for women and $<8.2 \mathrm{mmol} / \mathrm{L}$ for men. ${ }^{23}$

Operative data were extracted from the electronic medical records of the anesthesiologists. Duration and type of anesthesia and the American Society of Anesthesiologists (ASA) score were collected. The total number of packed red blood cells transfused during admission was retrieved from the blood transfusion center of our hospital. The type of procedure performed was noted and divided into four categories: minor amputation (amputation below the ankle joint or necrosectomy), major amputation (lower and upper leg amputation), bypass surgery (femoropopliteal, femorocrural, iliofemoral, and aortofemoral bypass), and femoral endarterectomy.

\section{Delirium}

The Amphia risk score for delirium was scored at admission. This is a screening tool developed for recognizing patients at risk for the development of a delirium during admission. ${ }^{1}$ The screening tool consists of five items that can be rated as absent or present with a maximum of 5 points. A score of 1 or higher was defined as high risk. After identifying frail patients at risk for delirium, primary nurses could consult specialized nurses for help in preventive actions for delirium. These nurses were intensively trained by geriatric medicine specialists. They further assisted the patient's primary nurse on the ward with appropriate nonmedical interventions such as the improvement of patient orientation, mobilization, and fall prevention.

In addition, the Delirium Observation Screening Scale (DOSS) was scored three times a day by trained nurses during regular care for at least the first 48 hours after admission (Supplementary material). ${ }^{24}$ Three or more points were considered highly indicative of delirium. All patients were visited on a daily basis by a physician. When delirium was present or suspected, a geriatrician was consulted and the diagnosis was confirmed based on the DSM-IV criteria. ${ }^{25}$
When required, the specialized nurse was able to consult the supervising geriatric medicine specialist. Then, a lowdose antipsychotic (Haloperidol ${ }^{\circledR}$ ) was prescribed based on the judgment of the consulting geriatrician. Duration of the delirium was defined as the total number of days with at least one DOSS score of 3 or more per 24 hours.

\section{Objectives}

The primary objective was to identify the possible risk factors for delirium in patients with critical limb ischemia undergoing surgery. The secondary objective was to study the effect of delirium on the following outcomes: the number of complications (medical and surgical adverse events), the length of stay in hospital and intensive care unit, mortality (30 days and 6 months), and the number of patients newly discharged to a nursing home.

Medical adverse events were defined as all complications in the postoperative period not directly related to the procedure performed. We divided medical adverse events into four categories: cardiac (myocardial infarction, cardiac failure, new onset of dysrhythmia), pulmonary (pneumonia, pulmonary embolism, acute respiratory insufficiency), neurological (cerebrovascular accident, transient ischemic attack, neurological deficit), and renal/urinary (urinary tract infection, urinary retention and renal impairment).

The surgical adverse events were defined as complications directly related to the procedure performed, such as wound infection, wound dehiscence, and significant bleeding.

Delirium-related additional costs based on prolonged hospital stay were based on regular costs of admission to the surgical ward (€343 per day).

\section{Statistical analysis}

Differences in categorical variables between patients with and without delirium were presented as relative frequencies (percentages) and tested using the chi-square test or Fisher's exact test. Differences of numerical variables (all skewed continuous variables) were presented as medians (interquartile ranges [IQRs]) and were tested using the Mann-Whitney $U$-test. The outcome variable (onset of delirium) was analyzed using conditional logistic regression analysis. The conditioning was based on the operation type (four strata). Variables entering the model were selected from the set of candidate variables based on a $P$-value $<0.40$ of their univariable relationship with delirium. After having entered all selected variables simultaneously in the conditional logistic regression model, a stepwise procedure was used where at each step the variable with the highest asymptotic $P$-value $>0.40$ was eliminated. 
Thereafter, elimination continued based on the highest exact $P$-value $>0.40$ using exact conditional logistic regression in order to avoid to overfitting. A cut-off of 0.40 for the $P$-value was chosen to avoid estimated regression coefficients being biased high (in absolute sense) and their standard errors being biased low. ${ }^{26}$ These finally selected explanatory variables were related to the delirium occurring pre- or postoperatively in the group of delirium patients using a similar exact conditional logistic regression analysis. Effects were presented by means of odds ratios (ORs) with 95\% confidence intervals (CIs). The relation between delirium and survival was analyzed using the Kaplan-Meier method and the log-rank test. A $P$-value of $<0.05$ was considered statistically significant. Delirium-related additional costs based on prolonged hospital stay were based on the costs of admission to the surgical ward (€343 per day). The impact of delirium on costs was estimated with linear regression analysis with correction for confounders found within this study after multivariable analysis. The univariable analysis and survival analyses were performed using the Statistical Package for the Social Sciences (IBM SPSS Statistics for Windows, Version 21.0 released 2012, Armonk, NY, USA). Multivariable analysis was performed with LogXact, Version 4.1 (Cytel Software Corporation, Cambridge, MA, USA).

\section{Results}

\section{Patient selection and characteristics}

A total of 92 patients with critical limb ischemia undergoing surgical treatment were included. The study population consisted of $58 \%$ men with a median age of 76 years. The baseline characteristics are summarized in Table 1.

\section{Delirium}

A total of 29 (32\%) patients developed a delirium during admission (Table 2). Of all patients undergoing delirium, $17(59 \%)$ developed a delirium prior to the operation. All these patients continued to have a delirium postoperatively. In twelve patients, delirium occurred postoperatively, with most of them (67\%) occurring on the first day. The median duration of delirium was 3 days. Patients who developed a delirium preoperatively had a significantly longer duration of delirium (median 6 days) compared to patients who developed a delirium postoperatively (median 2 days; $P=0.02$ ).

\section{Preoperative risk factors and factors on frailty related to delirium}

Nineteen $(66 \%)$ patients with delirium were octogenarians $(P<0.001)$. The identified factors related to delirium were
Table I Characteristics of all included patients with critical limb ischemia receiving surgery

\begin{tabular}{ll}
\hline Characteristic & $\begin{array}{l}\text { Rutherford classification } \\
\text { score 4-6, } \mathbf{n = 9 2}(\%)\end{array}$ \\
\hline Sex, male & $53(58)$ \\
Age, years, median (IQR) & $76(71-82)$ \\
Age 65-70 years & $20(22)$ \\
Age 70-79 years & $37(40)$ \\
Age $\geq 80$ years & $35(38)$ \\
Living status & \\
Nursing home & $21(23)$ \\
Daily care at home & $18(20)$ \\
Home without care & $53(57)$ \\
Comorbidity & \\
Cardiac disease & $55(60)$ \\
Pulmonary disease & $18(20)$ \\
Renal impairment & $10(11)$ \\
Neurological disease & $26(28)$ \\
Diabetes mellitus & $44(48)$ \\
Operation & $11(12)$ \\
Necrosectomy & $14(15)$ \\
Minor amputation & $18(19)$ \\
Major amputation & $10(11)$ \\
Femoral endarterectomy & $24(26)$ \\
Femoropopliteal bypass & $9(10)$ \\
Femorocrural bypass & $6(7)$ \\
Aortofemoral bypass &
\end{tabular}

Note: Data are presented as $\mathrm{n}$ and (\%), unless otherwise specified.

Abbreviation: IQR, interquartile range.

cardiac comorbidity $(P=0.010)$, delirium in medical history $(P=0.010)$, and visual impairment $(P=0.031)$. The daily use of alcohol $(P=0.017)$ and hypercholesterolemia $(P=0.028)$ were significantly more in the group without delirium (Table 3 ).

Univariable analysis identified several factors on frailty associated with delirium, such as physical impairment $(P=0.007)$ and living in a nursing home prior to admission $(P<0.001)$. The data are summarized in Table 3 .

\section{Perioperative factors}

A major amputation $(P=0.003)$ and preoperative anemia $(P=0.031)$ were significantly more in patients with delirium

Table 2 Onset and length of the delirium

\begin{tabular}{ll}
\hline & $\begin{array}{l}\text { Rutherford classification } \\
\text { score 4-6, } \mathbf{n = 9 2}(\%)\end{array}$ \\
\hline Delirium & $29(32)$ \\
Preoperative delirium & $17(59)$ \\
Postoperative delirium & $12(4 I)$ \\
Onset of postoperative delirium $(\mathrm{n}=\mathrm{I})$ & \\
Day I postoperation & $7(67)$ \\
Day 2 postoperation & $3(25)$ \\
Day 3 postoperation & - \\
Day 4 or more & $2(8)$ \\
Median length of delirium in days (IQR) & $3(\mathrm{I}-6)$ \\
\hline
\end{tabular}

Note: Data are presented as $\mathrm{n}$ and (\%).

Abbreviation: IQR, interquartile range. 
Table 3 Univariate analysis of possible risk factors in patients with critical limb ischemia in relation to the onset of delirium

\begin{tabular}{|c|c|c|c|}
\hline & $\begin{array}{l}\text { No delirium, } \\
n=63 \text { (\%) }\end{array}$ & $\begin{array}{l}\text { Delirium, } \\
\text { n=29 (\%) }\end{array}$ & $P$-value \\
\hline \multicolumn{4}{|l|}{ Sex } \\
\hline Male & $36(57)$ & $17(59)$ & 0.894 \\
\hline \multicolumn{4}{|l|}{ Age } \\
\hline Median age (years) $(\mathrm{IQR})^{\mathrm{a}}$ & $75(69-80)$ & 81 (76-86) & $0.00 \mathrm{I}^{\mathrm{b}}$ \\
\hline Age $65-70$ years & $17(27)$ & $3(10)$ & \\
\hline Age $70-79$ years & $30(48)$ & $7(24)$ & \\
\hline Age $\geq 80$ years & $16(25)$ & $19(66)$ & 0.003 \\
\hline \multicolumn{4}{|l|}{ Fontaine classification } \\
\hline Fontaine 3 & $24(38)$ & $4(13)$ & \\
\hline Fontaine 4 & $39(62)$ & $25(87)$ & 0.019 \\
\hline \multicolumn{4}{|l|}{ Comorbidity } \\
\hline Cardiac disease & $32(5 I)$ & $23(79)$ & 0.010 \\
\hline Pulmonary disease & $12(19)$ & $6(21)^{\prime}$ & 0.854 \\
\hline Renal impairment & $5(8)$ & $5(17)$ & $0.278^{c}$ \\
\hline Neurological disease & $16(25)$ & $10(34)$ & 0.369 \\
\hline Diabetes mellitus & $27(43)$ & $17(59)$ & 0.160 \\
\hline Hypertension & $38(60)$ & $12(4 I)$ & 0.090 \\
\hline Hypercholesterolemia & $28(44)$ & $6(21)^{\prime}$ & 0.028 \\
\hline \multicolumn{4}{|l|}{ Other predisposing factors } \\
\hline Delirium in medical history & $3(5)$ & $7(24)$ & $0.010^{c}$ \\
\hline Daily use of alcohol & $18(29)$ & $2(7)$ & 0.017 \\
\hline Visual impairment & $18(29)$ & $15(52)$ & 0.031 \\
\hline Hearing impairment & $22(35)$ & $11(38)$ & 0.780 \\
\hline \multicolumn{4}{|l|}{ Frailty factors } \\
\hline Physical impairment $^{\mathrm{d}}$ & $29(46)$ & $22(76)$ & 0.007 \\
\hline Undernourishment ${ }^{\mathrm{e}}$ & $|3 / 6|(2 \mid)$ & $10 / 24(42)$ & 0.057 \\
\hline Daily nurse visits at home & $1 \mathrm{l} / 55(20)$ & $7 / 16(44)$ & $0.093^{c}$ \\
\hline Living in nursing home & $8(13)$ & $13(45)$ & $<0.001$ \\
\hline
\end{tabular}

Notes: Values in parentheses are percentages unless indicated otherwise; ${ }^{2}$ values are median (interquartile range). $P$-value is calculated with chi-squared test. bMann-Whitney U-test; 'Fisher's exact test. 'Physical impairment is defined as a Katz-ADL score $<6 .{ }^{21}$ eUndernourishment is defined as a SNAQ-RC-score $\geq 3 .{ }^{22}$ Abbreviations: IQR, interquartile range; Katz-ADL, Katz Index of Independence in Activities of Daily Living; SNAQ-RC, Short Nutritional Assessment Questionnaire for Residential Care.
(Table 4). Bypasses procedures and a longer duration of anesthesia were significantly more in patients without delirium (Table 4).

\section{Multivariable analysis}

All variables of Tables 3 and 4 with a $P$-value $<0.40$ in relation to delirium entered simultaneously the conditional logistic regression model. Based on an asymptotic $P$-value $>0.40$, the following variables were eliminated from the model during the stepwise backward procedure: renal impairment, physical impairment, ASA score $\geq 3$, age, cardiac comorbidity, and history of delirium. Continuing the stepwise backward procedure using exact conditional regression analysis, the following variables were additionally eliminated based on an exact $P$-value $>0.40$ : daily nurse visits at home, Fontaine 4, neurological comorbidity, living in a nursing home, operation time, preoperative $\mathrm{Hb}$, and hypertension. Eventually, diabetes mellitus, SNAQ-RC $\geq 3$, general anesthesia, visual impairment, daily alcohol use, hypercholesterolemia, and packed cells transfusion remained in the estimated model with exact $P$-values $<0.40$, while operation type was adjusted for through conditioning. Only two factors were significantly associated with the onset of delirium: diabetes mellitus ( $\mathrm{OR}=6.23$; 95\% CI: 1.11-52.2; $P=0.035)$ and SNAQ-RC $\geq 3(\mathrm{OR}=5.55 ; 95 \%$ CI: $1.07-42.0$; $P=0.039$ ), adjusted for the other variables mentioned and presented in Table 5 and stratified by the operation type. The only variable selected for discriminating between pre- and postoperative delirium in the delirium patients with an exact $P$-value $<0.40$ was visual impairment, with a nonsignificant

Table 4 Perioperative variables in relation to onset of postoperative delirium in patients with critical limb ischemia having surgery

\begin{tabular}{|c|c|c|c|}
\hline & No delirium, $n=63(\%)$ & Delirium, n=29 (\%) & $P$-value \\
\hline ASA score $\geq 3$ & $43(68)$ & $26(90)$ & 0.028 \\
\hline Duration of anesthesia, median (IQR) & $\mid 42(27-2||)$ & $52(26-100)$ & $0.035^{\mathrm{b}}$ \\
\hline \multicolumn{4}{|l|}{ Type of anesthesia } \\
\hline General anesthesia & $56(89)$ & $28(96)$ & \\
\hline Regional anesthesia & $7(11)$ & I (4) & 0.226 \\
\hline \multicolumn{4}{|l|}{ Operation type } \\
\hline Minor amputation & $16(25)$ & $9(3 \mathrm{I})$ & 0.572 \\
\hline Major amputation & $7(\mathrm{II})$ & II (38) & 0.003 \\
\hline Bypass $^{c}$ & $32(5 \mathrm{I})$ & $7(24)$ & 0.016 \\
\hline Femoral endarterectomy & $8(13)$ & $2(7)$ & $0.714^{\mathrm{a}}$ \\
\hline \multicolumn{4}{|l|}{$\mathrm{Hb}$ and transfusion } \\
\hline Preoperative anemia $^{d}$ & $35 / 59(60)$ & $22 / 27(8 I)$ & 0.044 \\
\hline Preoperative $\mathrm{Hb}$, median (IQR) & $7.7(6.4-8.0)$ & $6.8(6.3-7.4)$ & $0.075^{b}$ \\
\hline Postoperative anemia $^{d}$ & $31 / 32(97)$ & $20 / 22(91)$ & $0.560^{\mathrm{a}}$ \\
\hline Postoperative Hb, median (IQR) & $6.45(5.7-6.9)$ & $6.2(5.7-6.9)$ & $0.832^{\mathrm{b}}$ \\
\hline Packed cells transfusion & $18(29)$ & $5(17)$ & 0.244 \\
\hline$\geq 3$ Packed cells transfused & $9(14)$ & $2(7)$ & $0.492^{\mathrm{a}}$ \\
\hline
\end{tabular}

Notes: Data are presented as $n$ and (\%), unless otherwise specified. P-value is calculated with chi-squared test. aFisher's exact test. ${ }^{D}$ Mann-Whitney U-test. 'Femoropopliteal, femorocrural, iliofemoral, and aortofemoral bypass. ${ }^{\mathrm{d}}$ Anemia is defined as a $\mathrm{Hb}<7.6 \mathrm{mmol} / \mathrm{L}$ for women and $<8.2 \mathrm{mmol} / \mathrm{L}$ for men. ${ }^{23}$

Abbreviations: ASA, American Society of Anesthesiologists; IQR, interquartile range; $\mathrm{Hb}$, hemoglobulin in mmol/L. 
Table 5 Results of an exact conditional logistic regression analysis of delirium, where the conditioning is on operation type (four strata)

\begin{tabular}{lll}
\hline Variables & OR $(95 \% \mathbf{C I})$ & $P$-value \\
\hline Diabetes mellitus & $6.23(1.1 \mathrm{I}-52.2)$ & 0.035 \\
SNAQ-RC $\geq 3$ & $5.55(1.07-42.0)$ & 0.039 \\
General anesthesia & $13.3(0.96-\infty)$ & 0.054 \\
Visual impairment & $3.72(0.98-15.6)$ & 0.055 \\
Daily alcohol use & $0.15(0.0 \mathrm{I}-1.07)$ & 0.062 \\
Hypercholesterolemia & $0.30(0.06-1.22)$ & 0.10 \\
Packed cells transfusion & $0.68(0.3 \mathrm{I}-1.23)$ & 0.27 \\
\hline
\end{tabular}

Notes: Data presented as ORs and their $95 \% \mathrm{Cl}$. Confidence limits and $P$-values are exact.

Abbreviations: OR, odds ratio; $\mathrm{Cl}$, confidence interval; SNAQ-RC, Short Nutritional Assessment Questionnaire for Residential Care.

effect in favor of a preoperative delirium (OR $=2.89 ; 95 \%$ CI: $0.55-17.9 ; P=0.27)$.

\section{Secondary outcomes}

The onset of delirium during hospital stay was not significantly related to more complications. The median hospital stay of patients with a delirium was 14 days $(\mathrm{IQR}=11)$ and was significantly longer compared to 8 days for patients without a delirium $(P=0.001)$ (Table 6).

The difference in survival between patients with and without a delirium was tested and illustrated using the Kaplan-Meier method (Figure 1). Overall mortality was higher in the delirium group than in the non-delirium group (log-rank test $P<0.0005$ ). Thirty-four percent of the patients with a delirium died within 6 months after surgery in contrast to $8 \%$ in the non-delirium group $(P=0.005)$. There was no difference in new admissions to a nursing home between both groups (Table 6).
Occurrence of delirium was related to an increase in hospital stay of 4.4 days after adjustment for identified independent predictors for delirium (visual impairment and diabetes mellitus). The additional delirium-related hospital stay corresponded to an increase of health care costs of $€ 2,195$ (95\% CI: €595-€3,794) per extra delirium. After correction for confounders (visual impairment and diabetes mellitus), the costs were an extra $€ 1,519$ (95\% CI: €717-€3,110) per delirium.

\section{Discussion}

In this longitudinal observational study, we attempted to find the predictors for the onset of delirium in patients with critical limb ischemia and to explore the impact on the related outcomes. Balasundaram and Holmes reviewed the literature regarding the incidence and etiology of delirium after elective vascular surgery. ${ }^{12}$ Incidences rates between $29 \%$ and $39 \%$ are reported ${ }^{9,13-15,27}$ However, only two of these studies reported data concerning patients with critical limb ischemia, with incidences rates of delirium between $42 \%$ and $44 \%$ after bypass surgery. ${ }^{9,15}$ We reported a $32 \%$ incidence rate of delirium in elderly patients with critical limb ischemia with a high mortality rate of $34 \%$ after 6 months.

The included potential risk factors for delirium influence each other and are often age-related (ie, visual impairment). The identified risk factors in this study are therefore related to the population studied and affected by the choice of potential confounders. After multivariable analysis, diabetes mellitus and undernourishment were identified as independent risk factors for delirium in this study.

Table 6 Length of hospital stay, ICU stay, and mortality in relation to onset of postoperative delirium in patients with critical ischemia

\begin{tabular}{|c|c|c|c|}
\hline Medical adverse events & No delirium, $n=63(\%)$ & Delirium, $n=29(\%)$ & $P$-value \\
\hline Cardiac & $2(3)$ & - & $1.0^{\mathrm{a}}$ \\
\hline Pulmonary & $2(3)$ & $2(7)$ & $0.588^{\mathrm{a}}$ \\
\hline Neurological renal/urinary & $2(3)$ & $-5(17)$ & $0.030^{\mathrm{a}}$ \\
\hline \multicolumn{4}{|l|}{ Surgical adverse events } \\
\hline Wound infection & $4(6)$ & $3(10)$ & $0.674^{\mathrm{a}}$ \\
\hline Re-bleeding requiring intervention & $\mathrm{I}(2)$ & - & $1.0^{\mathrm{a}}$ \\
\hline Wound dehiscence & I (2) & I (3) & $0.533^{\mathrm{a}}$ \\
\hline \multicolumn{4}{|l|}{ Length of stay } \\
\hline Total hospital stay in days, median (IQR) & $8(6-13)$ & $14(9-20)$ & $0.00 I^{b}$ \\
\hline Admission to ICU & $5(8)$ & $3(10)$ & $0.704^{a}$ \\
\hline ICU stay in days $\geq 2$ & - & I (3) & $0.315^{\mathrm{a}}$ \\
\hline \multicolumn{4}{|l|}{ Discharge destination } \\
\hline New nursing home client after discharge & $10(16)$ & $5(17)$ & $0.76 \mathrm{I}^{\mathrm{a}}$ \\
\hline
\end{tabular}

Notes: Data are presented as $\mathrm{n}$ and (\%), unless otherwise specified. $P$-value is calculated with chi-squared test. ${ }^{a}$ Fisher's exact test. ${ }^{b}$ Mann-Whitney $U$-test. Abbreviations: ICU, intensive care unit; IQR, interquartile range. 


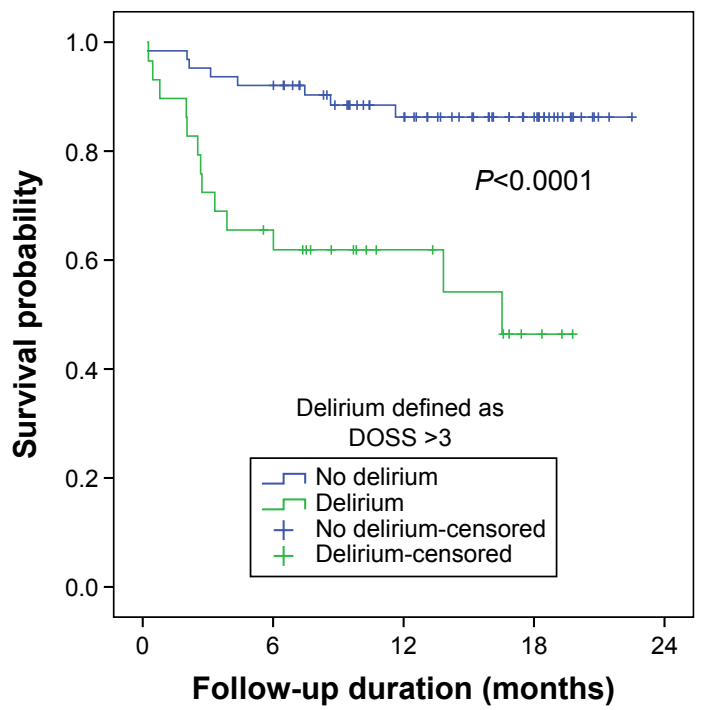

At risk:

$\begin{array}{lllll}\text { No delirium } & 63 & 58 & 39 & \\ \text { Delirium } & 29 & 18 & 9 & 3\end{array}$

Figure I Survival in relation to the onset of delirium in patients with critical limb ischemia.

Abbreviation: DOSS, Delirium Observation Screening Scale.

Preoperative delirium risk assessment is critical for identification of those patients who would most benefit from delirium prevention and surveillance protocols. Health care providers need to be aware of these identified risk factors for developing delirium. In these patients, timely nonpharmacological delirium prevention strategies should be initiated, with special attention for optimizing nutritional status.

An important finding of our study is that most patients suffering delirium developed it in the preoperative period $(59 \%)$. This is the first study to report that patients often develop a delirium in the preoperative period. All these patients continued to have a delirium postoperatively despite adequate treatment. For patients developing a delirium in the postoperative period, most developed it on the first postoperative day. This indicates the need for early preventive measures and maybe even standard preoperative consultation of a geriatrician in patients at risk for delirium.

In our study, pre- and postoperative $\mathrm{Hb}$ levels were not related with the onset of delirium after exact conditional logistic regression analysis. However, this could be explained by the high overall incidence of anemia in our study population (66\%). Despite the fact that anemia could not be related to the onset of delirium in this study, it is still related to higher postoperative complication rates. ${ }^{28}$ Therefore, preventive treatment of anemia may lead to a better outcome in operatively treated patients.
Interestingly, we report a lower incidence of delirium after bypass surgery (19\%), and bypass surgery was more frequently performed in the group without a delirium. In addition, duration of anesthesia was longer in patients without a delirium. In a study performed by Sasajima et al an incidence of $29 \%$ delirium after bypass surgery was reported. ${ }^{9,15}$ This difference could be explained by a certain selection bias. In our study, the indication for surgical (bypass) therapy was discussed in a multidisciplinary consultation based on the patient's condition. Patient's condition and frailty were key factors in deciding whether he/she was eligible for a certain type of operation. Patients in a better condition were more likely to receive a bypass procedure than patients in a poor and frail condition. Patient deemed unfit for surgery (bypass or amputation) or endovascular treatment received a conservative treatment with antibiotics and analgesics or had a primary amputation.

Patients having an endovascular revascularization were excluded in this study. Postoperative delirium may develop secondary to the extent of surgical trauma. Consequently, patients undergoing more invasive surgeries, such as bypass surgery, as well as major amputations may have higher rates of postoperative delirium. As Brosi et al reported, an endovascular first revascularization strategy should be preferred in octogenarians whenever possible because of the high perioperative mortality associated with surgery. ${ }^{29}$ Our finding may support this theory, especially for frail elderly who are at risk for delirium.

Sasajima et al identified critical limb ischemia as an independent risk factor for the onset of delirium after bypass surgery., ${ }^{9,15}$ To our knowledge, ours is the only study to report factors related to the onset of delirium in patients with critical limb ischemia receiving surgical treatment. The relation between critical limb ischemia and the onset of delirium is not yet fully known. However, critical limb ischemia is frequently associated with systemic atherosclerosis and its adverse effects on patient outcomes. ${ }^{18}$ Besides, systemic atherosclerosis contributes to cognitive decline among elderly patients, and cognitive impairment is a well-known risk factor for the onset of delirium..$^{30,31}$

Pol et al investigated the relation between systemic atherosclerosis and the onset of delirium but could not support this theory. ${ }^{32}$ Our study even reported an inverse relation between delirium and hypercholesterolemia. However, in this study, hypercholesterolemia was recorded based on the patient's medical record. This could explain the observed relationship in our study. In addition, the reported daily use of alcohol had an inverse relationship with the onset of delirium. This is in contrast to several other studies in which alcohol 
abuse was a predisposing factor for the onset of delirium. ${ }^{27}$ The results on self-reported alcohol consumption in this study may have led to a biased estimate of alcohol use. Possibly, there is an underestimation of self-reported drinking among individuals who drank more heavily. This study brings into question the accuracy of self-report measures, especially since other studies reported that alcohol consumption is an independent risk factor for delirium. ${ }^{33}$ Frail patients are more likely to develop a delirium. ${ }^{14,34,35}$ Patients with critical limb ischemia are often burdened with multiple comorbidities and are caredependent due to physical and cognitive impairment, leading to a frail condition. This was partially confirmed in our study on patients with critical limb ischemia receiving surgery.

\section{Limitations}

Most of our data were extracted from electronic medical records. Therefore, some data were missing and could not be obtained otherwise.

Several earlier studies confirmed medication as a risk factor for postoperative delirium, and therefore this should be included in further research. By using DOSS as the screening tool for delirium in hospitalized patients, we might have missed the hypoactive type of delirium. Therefore, our results could be an underestimation of the real incidence of delirium in patients with critical limb ischemia.

\section{Conclusion}

Delirium is a common adverse event in patients with critical limb ischemia undergoing surgery, with a devastating outcome in the long term. Most patients developed delirium preoperatively, which indicates the need for early recognition and preventive strategies in the preoperative period. This study identified undernourishment and diabetes mellitus as independent risk factors for delirium.

\section{Acknowledgment}

The authors would like to thank AJ van Gammeren, MD, $\mathrm{PhD}$, Department of Clinical Chemistry and Haematology, Amphia Hospital, for providing the blood transfusion data.

\section{Disclosure}

The authors report no conflicts of interest in this work.

\section{References}

1. Raats JW, van Hoof-de Lepper CC, Feitsma MT, Meij JJ, Ho GH, van der Laan L. Current factors of fragility and delirium in vascular surgery. Ann Vasc Surg. 2015;29(5):968-976.

2. Sieber FE. Postoperative delirium in the elderly surgical patient. Anesthesiol Clin. 2009;27(3):451-464.
3. Oh ES, Li M, Fafowora TM, et al. Preoperative risk factors for postoperative delirium following hip fracture repair: a systematic review. Int J Geriatr Psychiatry. 2014;30(9):900-910.

4. Smulter N, Lingehall HC, Gustafson Y, Olofsson B, Engstrom KG. Delirium after cardiac surgery: incidence and risk factors. Interact Cardiovasc Thorac Surg. 2013;17(5):790-796.

5. George J, Bleasdale S, Singleton SJ. Causes and prognosis of delirium in elderly patients admitted to a district general hospital. Age Ageing. 1997;26(6):423-427.

6. Inouye SK, Rushing JT, Foreman MD, Palmer RM, Pompei P. Does delirium contribute to poor hospital outcomes? A three-site epidemiologic study. J Gen Intern Med. 1998;13(4):234-242.

7. Kat MG, de Jonghe JF, Vreeswijk R, et al. Mortality associated with delirium after hip-surgery: a 2-year follow-up study. Age Ageing. 2011; 40(3):312-318.

8. Robinson TN, Raeburn CD, Tran ZV, Angles EM, Brenner LA, Moss M. Postoperative delirium in the elderly: risk factors and outcomes. Ann Surg. 2009;249(1):173-178.

9. Sasajima Y, Sasajima T, Uchida H, et al. Postoperative delirium in patients with chronic lower limb ischaemia: what are the specific markers? Eur J Vasc Endovasc Surg. 2000;20(2):132-137.

10. Inouye SK, Bogardus ST Jr, Charpentier PA, et al. A multicomponent intervention to prevent delirium in hospitalized older patients. $N \mathrm{Engl}$ J Med. 1999;340(9):669-676.

11. O’Mahony R, Murthy L, Akunne A, Young J, Guideline Development G. Synopsis of the National Institute for Health and Clinical Excellence guideline for prevention of delirium. Ann Intern Med. 2011;154(11):746-751.

12. Balasundaram B, Holmes J. Delirium in vascular surgery. Eur J Vasc Endovasc Surg. 2007;34(2):131-134.

13. Böhner H, Hummel TC, Habel U, et al. Predicting delirium after vascular surgery: a model based on pre- and intraoperative data. Ann Surg. 2003;238(1):149-156.

14. Pol RA, van Leeuwen BL, Visser L, et al. Standardised frailty indicator as predictor for postoperative delirium after vascular surgery: a prospective cohort study. Eur J Vasc Endovasc Surg. 2011;42(6): 824-830.

15. Sasajima Y, Sasajima T, Azuma N, et al. Factors related to postoperative delirium in patients with lower limb ischaemia: a prospective cohort study. Eur J Vasc Endovasc Surg. 2012;44(4):411-415.

16. Adam DJ, Beard JD, Cleveland T, et al; BASIL Trial Participants. Bypass versus angioplasty in severe ischaemia of the leg (BASIL): multicentre, randomised controlled trial. Lancet. 2005;366(9501):1925-1934.

17. Elsayed S, Clavijo LC. Critical limb ischemia. Cardiol Clin. 2015; 33(1):37-47.

18. Beckman JA, Creager MA. Critical limb ischemia and intermediate-term survival. JACC Cardiovasc Interv. 2014;7(12):1450-1452.

19. Saxena S, Lawley D. Delirium in the elderly: a clinical review. Postgrad Med J. 2009;85(1006):405-413.

20. Rutherford RB, Baker JD, Ernst C, et al. Recommended standards for reports dealing with lower extremity ischemia: revised version. $J$ Vasc Surg. 1997;26(3):517-538.

21. Weinberger M, Samsa GP, Schmader K, Greenberg SM, Carr DB, Wildman DS. Comparing proxy and patients' perceptions of patients' functional status: results from an outpatient geriatric clinic. J Am Geriatr Soc. 1992;40(6):585-588.

22. Kruizenga HM, de Vet HC, Van Marissing CM, et al. The SNAQ(RC), an easy traffic light system as a first step in the recognition of undernutrition in residential care. J Nutr Health Aging. 2010;14(2):83-89.

23. Desormais I, Aboyans V, Bura A, et al. Anemia, an independent predictive factor for amputation and mortality in patients hospitalized for peripheral artery disease. Eur J Vasc Endovasc Surg. 2014;48(2):202-207.

24. Schuurmans MJ, Shortridge-Baggett LM, Duursma SA. The delirium observation screening scale: a screening instrument for delirium. Res Theory Nurs Pract. 2003;17(1):31-50.

25. Kaplan HI, Sadock BJ. Kaplan and Sadock's Synopsis of Psychiatry. 8th ed. Philadelphia: Lippincott Williams \& Wilkins; 1998. 
26. Frank E, Harrel J. Regression Modeling Strategies. New York: Verlag; 2002.

27. Schneider F, Böhner H, Habel U, et al. Risk factors for postoperative delirium in vascular surgery. Gen Hosp Psychiatry. 2002;24(1): $28-34$.

28. Lasocki S, Krauspe R, von Heymann C, Mezzacasa A, Chainey S, Spahn DR. PREPARE: the prevalence of perioperative anaemia and need for patient blood management in elective orthopaedic surgery: a multicentre, observational study. Eur J Anaesthesiol. 2015;32(3):160-167.

29. Brosi P, Dick F, Do DD, Schmidli J, Baumgartner I, Diehm N. Revascularization for chronic critical lower limb ischemia in octogenarians is worthwhile. Eur J Vasc Endovasc Surg. 2007;46(6): 1198-1207.

30. Kalish VB, Gillham JE, Unwin BK. Delirium in older persons: evaluation and management. Am Fam Physician. 2014;90(3):150-158.
31. Vinkers DJ, Stek ML, van der Mast RC, et al. Generalized atherosclerosis, cognitive decline, and depressive symptoms in old age. Neurology. 2005;65(1):107-112.

32. Pol RA, van Leeuwen BL, Reijnen MM, Zeebregts CJ. The relation between atherosclerosis and the occurrence of postoperative delirium in vascular surgery patients. Vasc Med. 2012;17(2):116-122.

33. Patti R, Saitta M, Cusumano G, Termine G, Di Vita G. Risk factors for postoperative delirium after colorectal surgery for carcinoma. Eur J Oncol Nurs. 2011;15(5):519-523.

34. Eeles EM, White SV, O'Mahony SM, Bayer AJ, Hubbard RE. The impact of frailty and delirium on mortality in older inpatients. Age Ageing. 2012;41(3):412-416.

35. Quinlan N, Marcantonio ER, Inouye SK, Gill TM, Kamholz B, Rudolph JL. Vulnerability: the crossroads of frailty and delirium. $J$ Am Geriatr Soc. 2011;59(suppl 2):S262-S268. 


\section{Supplementary material}

\begin{tabular}{ll}
\hline DOSS (Delirium Observation Screening Scale) \\
\hline 1 & Dozes during conversation or activities \\
2 & Easily gets distracted by stimuli from the environment \\
3 & Maintains attention to conversation or answer \\
4 & Does not finish question answer \\
5 & Gives answers which do not fit the question \\
6 & Reacts slowly to instructions \\
7 & Thinks to be somewhere else \\
8 & Knows which part of the day it is \\
9 & Remembers recent event \\
10 & Is picking, disorderly, restless \\
11 & Pulls intravenous tubes, feeding tubes, catheter \\
12 & Is easy or sudden emotional \\
13 & Additive or visual hallucinations \\
\hline
\end{tabular}

Notes: If present, I point. Rate three times per day.

\section{Publish your work in this journal}

Clinical Interventions in Aging is an international, peer-reviewed journal focusing on evidence-based reports on the value or lack thereof of treatments intended to prevent or delay the onset of maladaptive correlates of aging in human beings. This journal is indexed on PubMed Central, MedLine,
CAS, Scopus and the Elsevier Bibliographic databases. The manuscript management system is completely online and includes a very quick and fair peer-review system, which is all easy to use. Visit http://www.dovepress. com/testimonials.php to read real quotes from published authors. 